\title{
A EXPERIÊNCIA EMOCIONAL DE AUTORAS DE MOMMY BLOGS
}

\author{
Andréia de Almeida Schulte \\ Pontifícia Universidade Católica de Campinas \\ Sueli Regina Gallo-Belluzzo \\ Pontifícia Universidade Católica de Campinas \\ Tânia Maria José Aiello-Vaisberg \\ Pontifícia Universidade Católica de Campinas e Universidade de São Paulo
}

\begin{abstract}
Resumo
A presente pesquisa objetiva investigar psicanaliticamente a experiência emocional de mulheres que vivenciam a maternidade em contextos nos quais a opressão feminina apresenta caráter estrutural. Justifica-se tendo em vista a produção de conhecimentos relevantes para a clínica psicológica, vertentes psicoterapêuticas e psicoprofiláticas, e para debates que visam transformações sociais. Organiza-se ao redor do uso do método psicanalítico no estudo de dez postagens de mommy blogs, cuja consideração permitiu a produção interpretativa de dois campos de sentido afetivo-emocional ou inconsciente relativo às condutas: "dedicando-se exclusivamente" e "conciliando atividades". O quadro geral sugere uma forte vinculação entre maternidade e sofrimento, ligando-se às exigências contemporâneas de uma maternidade enquanto única missão e destino feminino, mas de também desenvolver carreira profissional e contribuir financeiramente de modo significativo para o sustento familiar. Trata-se de uma situação que ocorre em diferentes classes, contextos culturais e situações geopolíticas, afetando não apenas a mulher, mas toda a família.

Palavras-chave: maternidade; contemporaneidade; sofrimento; psicanálisemetodologia.
\end{abstract}

\section{THE EMOTIONAL EXPERIENCE FROM MOMMY BLOGGERS' AUTHORS}

\begin{abstract}
This essay aims to investigate psychoanalytically the emotional experience of women who experienced motherhood in contexts in which female oppression has a structural character. It is justified by the production of relevant knowledge for psychological clinic, psychotherapeutic and psychopathological strands, also for debates that aim social transformations. It is organized within the use of the psychoanalytic method by studying ten postings available in mommy blogs whose consideration allowed the interpretive production of two affective-emotional meaning fields or relative unconsciousness related to the conducts: "dedicating yourself" and "reconciling activities ". The overall frame suggests a strong relation between motherhood and suffering, which is linked to contemporary demands of a motherhood as their only mission and destiny, but also to develop a professional career, contributing financially to the family's livelihood. This situation occurs in different social classes, cultural contexts, and geopolitical situations, affecting not only the woman herself, but also the entire family.
\end{abstract}

Keywords: motherhood; contemporaneity; suffering; psychoanalysis-methodology. 


\title{
LA EXPERIENCIA EMOCIONAL DE LAS AUTORAS DE MOMMY BLOGS
}

\begin{abstract}
Resumen
Esta investigación objetiva investigar psicoanalíticamente la experiencia emocional de mujeres que experimentan la maternidad en contextos donde la opresión femenina tiene carácter estructural. Es justificada con la producción de conocimiento relevante en la clínica psicológica, pendiente psicoterapéuticas y psicoprofilácticas, y para las discusiones destinadas a la transformación social. Se organiza en torno a la utilización del método psicoanalítico en el estudio de diez mensajes de mommy blogs, cuya consideración permitió la producción interpretativa dos campos de sentido afectivo y emocional 0 inconscientes relativos a las conductas: "la dedicación exclusiva" y "conciliación de actividades". El panorama sugiere una fuerte relación entre la maternidad y el sufrimiento, unido a las demandas contemporáneas que enfocan la maternidad como su única misión y destino, pero también exigen desarrollar una carrera significativa, contribuyendo financieramente a los gastos familiares. Esta es una situación que se produce en diferentes clases, contextos sociales y culturales, como en diferentes situaciones geopolíticas, que al fino afecta no sólo a la mujer, sino a toda la familia.
\end{abstract}

Palabras clave: maternidad; contemporaneidad; sufrimiento; psicoanálisismetodología.

\section{INTRODUÇÃO}

\section{Apresentação}

Considerando que a psicopatologia psicanalítica se fundamenta no complexo esquema causal conhecido como séries complementares (Freud, 1917/1996), segundo o qual todos os quadros de sofrimento emocional, neuróticos, psicóticos e borderlines, derivariam da interação entre constituição, experiência emocional infantil e acontecimentos da vida adulta, não surpreende constatar que a maternidade seja questão que vem recebendo atenção de pesquisadores da área da psicologia há muito tempo. De fato, como vivemos numa sociedade na qual os cuidados das crianças são organizados como atribuição da mãe biológica, a vida delas se revela fortemente afetada pela relação mãe-filho.

Entretanto, desde os inícios da psicanálise, a condição feminina transformou-se bastante na sociedade ocidental, a partir da instauração de certas condições históricas e da ação dos movimentos feministas (Badinter, 1985, 2010; Chodorow, 1978; Hollway, 2006). Winnicott (1945/2000; $1956 / 2000 ; 1960 / 1998 ; 1963 / 1983 ; 1966 / 1999)$, inclusive, autor que dedicou grande atenção à vida do bebê e à mãe real, depositou na figura materna a responsabilidade de um bom desenvolvimento - ou não - dos filhos. Desta forma, a sociedade - com o respaldo científico da época - considerou a mulher, durante muito tempo, como a exclusiva cuidadora de crianças e, consequentemente, a responsável pelos problemas e dificuldades que as crianças, porventura, pudessem apresentar, ignorando a convivência com o pai, com outros membros das famílias nuclear e extensa, com a instituição de ensino e com a comunidade (Aiello-Vaisberg, 2017). 
Tais mudanças, envolvendo a maior participação da mulher em espaços públicos e no mercado de trabalho, certamente vem afetando o exercício da maternidade, principalmente porque a antiga divisão de trabalho doméstico tem persistido majoritariamente. Desse modo, ou a família nuclear adota a forma tradicional de organização, com o homem se encarregando do sustento financeiro do lar e a mulher se responsabilizando pelas tarefas domésticas, que incluem o cuidado dos filhos, ou adota um novo modelo, no qual ambos os cônjuges trabalham, entretanto, a mulher ainda segue se responsabilizando pela casa e pelos filhos. Ambas as escolhas apresentam conveniências e inconveniências, causando sempre algum desconforto emocional para a mulher, o qual pode ser precisamente definido como sofrimento social na medida em que vinculado ao modo como a sociedade organiza as relações de gênero e a criação dos filhos.

Ora, parece-nos importante lembrar que a experiência infantil se apresenta intensamente configurada a partir da relação com a mãe como primeiro objeto de amor da criança (Freud, 1925/1996). Sendo assim, o modo como a mulher vivencia sua própria vida, na qual se inclui a experiência emocional de ser mãe, provavelmente gerará efeitos importantes na vida de seus filhos, que poderão repercutir em seu futuro como adultos. Dessa forma, pesquisas sobre a experiência materna, como a presente, parecem-nos necessárias e importantes.

Mais especificamente, parecem-nos interessantes trabalhos que possam abordar a experiência de ser mãe na contemporaneidade como modo específico de sofrimento social. A nosso ver, essa associação pode ser articulada conceitualmente de duas diferentes maneiras. De um lado, pode ser pensada como algo que atingiria apenas alguns grupos sociais, como mulheres pobres, mulheres negras ou mulheres vítimas de violência doméstica. De outro lado, pode ser concebida de forma ampliada, como sofrimento que impactaria todas as mulheres que vivem em sociedades nas quais a opressão feminina possui caráter estrutural, independentemente do contexto social, cultural ou econômico em que vivem (Schulte, Gallo-Belluzzo, \& Aiello-Vaisberg, 2016a). De nosso ponto de vista, ambas as visões correspondem a questões importantes. Portanto, neste momento, optamos por abordar maternidade e sofrimento social de acordo com esta segunda forma de articulação.

\section{Sofrimento Social}

O reconhecimento de dificuldades importantes que acompanham a maternidade não significa que neguemos que a experiência de ser mãe seja fonte de profundas gratificações para a mulher. Tal fato, aliás, é, segundo nossa experiência, claramente percebido pelos adultos, sejam homens ou mulheres, mães ou não mães, pelos adolescentes e mesmo pelas crianças. 
Entretanto, são, realmente, muito evidentes as dificuldades e sofrimentos das mães que enfrentam condições de pobreza, que se caracterizam por problemas laborais, de moradia, saneamento, alimentação, transporte, educação e saúde (Scabio, 2016; Amaral \& Bispo, 2016). Igualmente eloquentes são aquelas situações de doenças graves e morte de filhos, que podem atingir tanto as camadas pobres como as abastadas (Nascimento \& Faro, 2015; Segeren \& Françoso, 2014). Tais situações são muito importantes. As primeiras correspondem a sofrimentos sociais entendidos segundo uma acepção precisa, mas restrita. As segundas são sofrimentos humanos, que podem ser acentuados quando vividos em condições econômicas desfavoráveis, pois se a doença é sempre difícil, deficiências na assistência médica tornam-na mais sofrida.

Contudo, quando examinamos a realidade social a partir da psicologia concreta (Bleger, 1963/1984), a qual considera que as condutas humanas emergem a partir de campos relacionais, que se inserem em contextos sociais, econômicos, culturais, históricos e geopolíticos, e lançamos nosso olhar para a condição de vida das mulheres-mães brasileiras (Corbett, 2014), somos levados a rever a ideia de que apenas algumas sofrem, enquanto outras apenas usufruem a felicidade de terem filhos. Chegamos, assim, a aventar a possibilidade de que a articulação entre maternidade e sofrimento, no Brasil contemporâneo, seja menos circunstancial e mais estrutural, permitindo, desse modo, que cogitemos sobre a possibilidade de nos encontrarmos diante do que tem sido conceituado como sofrimento social (Ambrósio, Aiello-Fernandes, \& Aiello-Vaisberg, 2013). Desta forma, cremos que a complexidade da vida não impede que a experiência da maternidade seja acompanhada de sofrimento.

A expressão sofrimento social foi inicialmente utilizada na França, sob a pena de Dejours (1980/1993; 1998), focalizando especificamente sofrimentos vivenciados no contexto laboral. Posteriormente, ganhou certo destaque o trabalho de Kleinman, Das e Lock (1997), no qual o conceito se ampliou para abranger variadas situações que afetam grupos que vivem em condições sociais adversas. Mais recentemente, a questão foi retomada, de modo, a nosso ver, bastante produtivo, novamente na França, por Renault (2004; 2008), que distinguiu como componentes principais do sofrimento social, o desamparo, a humilhação e a injustiça. Entretanto, em que pese nosso reconhecimento acerca do valor dessas contribuições, não temos dúvidas em afirmar que Bleger (1963/1984) pode ser considerado um importante precursor dessa área de estudos, pois, ainda que a expressão sofrimento social não figure em sua obra, é correto afirmar que nossa visão acerca desse fenômeno baseia-se inteiramente na perspectiva de sua psicologia concreta, segundo a qual condutas humanas emergem de campos relacionais que se inscrevem em contextos sociais. 


\section{A maternidade e a clínica psicológica}

No Brasil a demanda pelo cuidado, por meio da atenção psicológica, é advinda de dois perfis socioeconômicos. O primeiro, de pacientes que podem assumir os custos de um tratamento particular. O segundo, provém de classes desfavorecidas que recebem encaminhamento de profissionais de várias áreas para atendimento psicológico em instituições públicas (Aiello-Vaisberg, 2001).

Neste cenário, a clínica-escola, concebida como organização pública, apresenta-se como importante alternativa que viabiliza cuidado psicológico gratuito ao segundo tipo de perfil socioeconômico. Nessa instituição somos impactados pela relevância que a maternidade assume, tanto na vida das mulheres, como na vida das crianças, haja vista a predominância de mulheres na procura desses serviços, sejam elas as mães ou suas substitutas.

Para articularmos tal tópico, apresentamos algumas pesquisas com vistas a conhecer as demandas da clínica-escola que apontam para dois tipos principais de pacientes. O primeiro como sendo constituído por crianças em atendimentos infantis (Ancona-Lopez, 1983; Merg, 2008; Yoshida, Gatti, \& Xavier, 1994), denotando o foco na "criança-problema" e colocando em segundo plano o contexto em que surgem as condutas iniciais que a levaram ali. Em segundo lugar, está o atendimento à mulher, como podemos verificar nas pesquisas a seguir.

Affonso e Mota (2002), por intermédio de análise de prontuários de crianças de 2 a 12 anos, atendidas em uma clínica-escola do interior de São Paulo, objetivam associar as queixas com o relacionamento familiar. Os autores concluíram que os diferentes problemas apresentados pelas crianças estavam relacionados a tipos específicos de vínculo pais-filhos, apontando para a necessidade de atendimento psicológico dos pais na resolução das dificuldades infantis.

No trabalho de Melo e Perfeito (2006), podemos vislumbrar com mais clareza o papel da mulher no atendimento infantil. Segundo os autores, seria "praticamente impossível discutir atendimentos infantis, sem abordar o papel parental e familiar em relação às dificuldades e saúde emocional das crianças" (p. 240). O que chama a atenção dos autores é que, diferentemente de estudos anteriores, que constataram que a demanda de atendimento infantil provinha, predominantemente, da instituição educacional, neste, a procura pelo atendimento foi, predominantemente, iniciativa dos pais. Por fim, os autores indicam que em mais de $50 \%$ dos casos analisados, foi possível identificar unicamente questões familiares e/ou falha no suporte ambiental, defendendo então, que dentro de uma perspectiva intersubjetiva, deve-se considerar fortemente a relação pais-criança. Logo, defendem a necessidade de cuidar dos pais, sobretudo da mãe, que é a principal responsável pelos cuidados com as crianças nestes contextos sociais. 
Tais pesquisas mostram que a maternidade é atravessada por sofrimento nos mais variados modos, também denota a ausência paterna quando aponta, consistentemente, para o cuidado infantil ser realizado, quase exclusivamente, por mulheres. Os sofrimentos engendrados pela maternidade são pesquisados em vários âmbitos e com diferentes recortes. Em Granato e Aiello-Vaisberg (2011), entramos em contato com mulheres que não têm acesso fácil ao serviço psicológico e, por meio de trabalho com atendimento grupal, as autoras têm a proposta de ajudá-las a lidar com tais sofrimentos. Já em Granato e AielloVaisberg (2009), o foco está em mulheres em estados de colapso psíquico relacionados à maternidade e suas dificuldades para se preocuparem com seus filhos. Couto, Tachibana e Aiello-Vaisberg (2007) pesquisaram acerca da experiência emocional de mães de crianças com síndrome de Down, defrontando-se com mães que experimentavam um grande sofrimento emocional e a dificuldade de aceitar o diagnóstico da criança. Outro viés que aponta para o sofrimento da mulher-mãe, é o trabalho de Corbett (2014) sobre mulheres que sofrem violência doméstica.

Os trabalhos acima apontam para a questão de que é no atendimento psicológico que essas mães conseguem falar sobre seus sofrimentos, como também encontram suporte emocional que pode lhes proporcionar alívio, oferecendo-Ihes a possibilidade de se apropriarem de forma genuína da maternidade. Portanto, é neste ambiente da clínica psicológica que, ao entrarmos em contato com os dramas vividos por tantas mulheres, chegamos à compreensão de que o sofrimento materno pode se manifestar também em vários ambientes e é consequência de uma construção social em que a mulher é quase inteiramente responsável por toda e qualquer situação que envolva o cuidado de seus filhos, o que também a faz sentir-se responsável, analogamente, a tudo de bom ou ruim que acontecer a eles. Nesse sentido, cremos que a clínica psicológica reflete a cultura e revela que, hoje, muito sofrimento parece decorrer de ideais da nossa sociedade, que foram transformados em imperativos.

\section{A maternidade e o feminismo}

Acreditamos que uma discussão sobre a mulher inclui, necessariamente, a consideração do movimento feminista. Trata-se de um movimento social e político de grande importância, que tem como pilar a busca de equidade entre os sexos (Garcia, 2011). Partindo deste ponto, germinam outros temas e um deles é a questão da maternidade.

Cabe salientar que, como não existe um modelo único de feminismo, pois este movimento é plural, não há apenas um enfoque feminista acerca da maternidade, sendo essa valorizada em alguns períodos e, em outros, vista como uma função social que favorece certas formas de opressão feminina (Badinter, 2010; Collin \& Laborie, 2009; Garcia, 2011). O começo do que conhecemos sobre este movimento é denominado como primeira onda do feminismo. Esta foi 
iniciada na segunda metade do século XIX pelas sufragistas europeias, grupo este que se constituía por mulheres brancas e de classe média, que lutaram pelo direito do voto feminino e também pelo direito de trabalhar sem autorização marital (Fougeyrollas-Schwebel, 2009). É interessante pontuar que a mulher dessa mesma época, entretanto de uma classe social inferior, já trabalhava, muitas vezes sem autorização do cônjuge, pois seus ganhos eram indispensáveis ao sustento familiar (Pinsky \& Pedro, 2012). Este fato deixa clara a complexidade das inter-relações que permeiam a opressão feminina. Também, nessa fase não havia um interesse específico em discutir ou questionar a maternidade, pois esta era considerada, à época, um fenômeno natural, mera consequência do casamento (Badinter, 2010; Vázquez, 2014).

A partir de 1960, com o advento da segunda onda do feminismo, fortemente calcada na contribuição de Beauvoir (1949/1980), ocorre uma redefinição da agenda feminista, que passa a incluir uma preocupação com a maternidade (Tain, 2005). O modo como tal questão veio a ser abordada esteve decididamente influenciado pelo posicionamento de Beauvoir (1949/1980), que pode ser sintetizado na fórmula feliz segundo a qual ninguém nasce mulher, pois essa seria uma condição socialmente construída.

Neste momento do feminismo o tema da maternidade esteve muito presente nas discussões e no ativismo político, o que resultou na reflexão sobre seu significado, tanto na sociedade quanto em âmbito privado, vale dizer, na família nuclear. A politização da vida quotidiana, empreendida pelas feministas denominadas radicais, questionou com vigor as relações com os homens dentro do casamento e também a maternidade. É nesse contexto que ganha força a luta pelo acesso à contracepção, por meio das pílulas anticoncepcionais, bem como o direito ao aborto, ou seja, a defesa da não maternidade por esta ser considerada, por estas feministas, como opressiva (Miguel \& Biroli, 2014; Scavone, 2001; 2004).

$\mathrm{Na}$ terceira onda do movimento feminista, que teve inicio na década de 1980 e mantém-se vigente até os dias atuais (Scavone, 2001), a maternidade, que fora renegada pelas feministas radicais do período anterior, ganhou um novo significado, passando a ser rediscutida. É possível distinguir dois diferentes momentos de como a maternidade é considerada nesta fase.

O primeiro, concentra-se na oposição ao radicalismo das feministas da segunda onda, que combatiam veementemente a maternidade. Por este motivo, talvez não cause estranheza constatar que se define por uma radical defesa da maternidade como dedicação integral aos filhos, segundo modelo francamente conservador. Para Badinter (2010), a figura que aqui emerge seria a da boa mãe ecológica, herdeira do discurso que, nas décadas de 1970 e 1980, pregaram um retorno à natureza, bem como a "ruptura com comportamentos consumistas, fruidores, egoístas e amorais" (p. 47). Esta mãe também rejeitaria os avanços tecnológicos relativos à maternidade, tais como ambientes hospitalares, parto 
cesáreo e o uso de analgesias, bem como artefatos que auxiliam as atividades do cuidado infantil, tais como as fraldas descartáveis e a mamadeira.

Evidentemente, tais visões têm como base a crença de que a mulher seria naturalmente preparada para ser mãe, dar à luz, amamentar e cuidar de seu bebê (Badinter, 2010). Podemos, assim, convir que se trata de um movimento de caráter reacionário, centrado na retomada de alguns mitos, segundo os quais o ser humano definir-se-ia basicamente como ser natural, isolado e abstrato (Bleger, 1963/1984).

A outra vertente da terceira onda se dá por meio da superação da naturalização da maternidade e da rejeição completa dos ideários da segunda onda. Esta fase se caracteriza pela ideia de que ter filhos é uma opção a ser livremente escolhida ou rejeitada pela mulher que, em situação de casamento, pode ouvir o companheiro, mas não se sente compelida a engravidar contra a própria vontade. Um leque de reivindicações acompanha a tomada deste posicionamento, entre as quais lembramos a de cuidados pré-natais de qualidade, a proteção de mulheres e garotas contra a violência doméstica e os direitos trabalhistas, incluindo a licença-maternidade (Miguel \& Biroli, 2014). Por fim, as feministas dessa fase propõem uma atuação conjunta do casal no cuidado e na criação dos filhos, tirando da mulher a responsabilidade praticamente exclusiva pelo bem-estar das crianças e liberando-a para outras atividades, principalmente no mundo público (Scavone, 2004).

Entretanto, malgrado as mulheres tenham lutado, e ainda lutam, por uma atuação conjunta para o cuidado infantil, parece-nos que esta situação está longe de se realizar, ao menos em nosso país, de forma realmente expressiva. É o que observamos no relatório do Fórum Econômico Mundial (WEF) de 2016, no qual, além de denotar questões de desigualdade corporativa de gênero, há a percepção politica e social de que a mulher seja a melhor cuidadora, não somente de crianças, como também da família e de idosos, ainda que a mulher brasileira esteja galgando melhores condições educacionais que os homens e, assim, preparando-se melhor para suas carreiras. Por outro lado, não negamos que em certos contextos sociais, caracterizados por um maior grau de instrução e pequeno número de filhos, sejam adotadas práticas de divisão de tarefas domésticas e, consequentemente, há a possibilidade de a mulher se engajar no mundo corporativo com maior suporte familiar.

A partir do exposto, poderíamos apontar várias problemáticas acerca da maternidade que se entrelaçam com a questão de gênero, tais como: diferença salarial, ascensão profissional, cuidado infantil, possibilidades de estudo, diferenças de classe etária, étnica, de orientação sexual, entre tantas outras. Todas, entretanto, construídas socialmente, provocando a persistência da desigualdade, o que certamente causa injustiça e, consequentemente, mais sofrimento social. Desta forma, não é difícil lucubrar que as dificuldades relativas à maternidade, muito embora atravessem as questões construídas socialmente, 
dão-se em diferentes intensidades nas distintas camadas sociais. Logo, compreendemos que este movimento denunciou que o fenômeno do patriarcado se reproduz na responsabilização, praticamente exclusiva, das mulheres pelos cuidados com seus filhos e que tal tarefa impossibilitaria, ao menos parcialmente, a participação da mulher na esfera pública, melhor dizendo, na realização de atividades para além daquelas exigidas em relação ao cuidado de crianças.

Finalizamos afirmando que a maternidade, no mundo contemporâneo, pode ser considerada como experiência emocional complexa que tanto provê gratificação e alegrias profundas como também se associa ao sofrimento. Esperamos que a junção das frentes escolhidas componha um argumento convincente no sentido de que é preciso distinguir dois tipos de sofrimentos maternos. Primeiro, aqueles infortúnios que se abatem sobre algumas mulheres, quando se defrontam com situações tais como doenças próprias ou dos filhos, ou estados de pobreza que as impedem de prover as necessidades familiares. 0 segundo, como sofrimento social que, intimamente relacionado às questões de gênero, atravessa situações de classe e raça, entre outras.

\section{MÉTODO}

Esta pesquisa se organiza como estudo qualitativo, na medida em que voltado para o estudo de significações de experiências e atos humanos, compreendidos como fenômenos que se dão de modo vincular e socialmente contextualizados (Ambrósio et al., 2013). Adotamos o referencial psicanalítico, mais precisamente a psicanálise dramática e intersubjetiva proposta por Bleger (1963/1984) que, mediante o uso do método psicanalítico de investigação, elabora modelos compreensivos, que incluem a dimensão inconsciente sobre fenômenos humanos. Todavia, é importante lembrar que parece haver mais de um modo de compreensão da psicanálise. Na verdade, seu surgimento se deu, efetivamente, quando a hipnose foi abandonada por Freud e a associação livre de ideias foi proposta aos seus pacientes (1895/1996; 1914/1996), e assim consagrou a invenção do método. Importante destaque sobre a importância da dimensão investigativa da psicanálise foi feita em 1922 quando Freud, em Dois Verbetes de Enciclopédia, escreve sobre sua criação:

(1) de procedimento para a investigação de processos mentais que são quase inacessíveis por qualquer outro modo. (2) um método, (baseado na investigação) para o tratamento de distúrbios neuróticos e (3) uma coleção de informações psicológicas obtidas ao longo dessas linhas, e que gradualmente se acumula numa nova disciplina científica. (Freud, 1922/1996, p. 287).

Logo, a partir da definição do próprio autor, a Psicanálise deve ser considerada como um método investigativo, do qual deriva uma técnica e uma teoria. Herrmann (1979/2004), abordando tal questão, defende e fundamenta 
que a realização de pesquisas acadêmicas não deveria usar apenas material de atendimento clínico, na esteira, diga-se de passagem, do que já fizera o próprio criador do método quando abordou obras artísticas e literárias. De forma didática, Herrmann articula três diferentes formas de uso da psicanálise em pesquisas - para apontar criticamente que apenas uma dessas formas poderia ser legitimamente considerada como investigação psicanalítica. A primeira corresponde a pesquisas teóricas, que trabalham com textos e seu objeto de estudo é o próprio texto psicanalítico. A segunda forma abrange pesquisas que se alinham aos pressupostos da perspectiva quantitativa. Nestas, o material é produzido mediante o uso de instrumentos, tais como questionários, testes e escalas, cujos resultados são discutidos à luz de teorias psicanalíticas já estabelecidas. Por fim, a terceira modalidade de pesquisas, que se reivindicam como psicanalíticas, são aquelas que se definem não pela adesão a esta ou aquela teoria, mas por meio do método psicanalítico. Neste último caso, a atenção flutuante e a associação livre são colocadas em marcha em diversas fases do processo investigativo, utilizando material produzido dentro ou fora de settings de atendimento.

É neste último modelo que fundamentamos nossa pesquisa psicanalítica e, para tanto, utilizamo-nos das palavras de ordem metodológica herrmaniannas: "deixar que surja", "tomar em consideração" e "completar a configuração de sentido". Tais palavras de ordem servem tanto para facilitar a formação de novos pesquisadores quanto para explicar com clareza as nossas pesquisas para os leitores que adotam outras perspectivas teóricas, tornando-se assim, um caminho facilitador para a interpretação psicanalítica de produções humanas com vistas a "criar/encontrar" campos de sentido afetivo-emocional.

$\mathrm{Na}$ presente pesquisa utilizamos uma forma de operacionalização do método psicanalítico que possibilita seu uso fora do setting de atendimento (Gallo-Belluzzo, Corbett, \& Aiello-Vaisberg, 2013; Schulte et al., 2016a, b). Metodologicamente, optamos pela investigação psicanalitica de comunicações disponíveis em blogs pessoais e brasileiros, assinados por pessoas que se identificam como mulheres e mães, estes são comumente denominados Mommy Bloggers (Petersen, 2015; Webb \& Lee, 2011). Tal escolha se deu ao nos indagarmos sobre a natureza de uma produção humana que pudesse expressar a experiência emocional relativa a um certo tema, no caso a experiência sobre ser mãe, mantendo a máxima liberdade expressiva e sem a necessidade de interposição de uma situação proposta (Schulte, 2016; Schulte et al., 2016a, b).

Politzer (1928/1998), em cuja obra inspirou-se Bleger (1963/1984) para propor sua psicologia da conduta, acreditava que o verdadeiro objeto de estudo da psicologia - e da psicanálise - seria o drama, vale dizer, a experiência vivida. Trabalhamos com o conceito de experiência emocional partindo deste ponto de vista, uma vez que estamos interessados em conhecer a realidade pessoal de indivíduos e/ou coletivos acerca de questões humanas específicas. Trata-se, 
portanto, de focalizar a experiência vivida, expressão com a qual queremos designar o que Politzer referiu como "fato psicológico em primeira pessoa", incluindo, assim, os múltiplos sentidos, conscientes e não conscientes. Pensadas em sentido amplo, todas as condutas humanas têm caráter narrativo, na medida em que contam o drama vivenciado. Desse modo, não é difícil compreender que a natureza de uma postagem em blog pessoal é, nada menos, que um meio contemporâneo de narrar uma experiência vivida.

Operacionalizamos o método psicanalítico em termos da diferenciação de quatro procedimentos investigativos, a saber: procedimento investigativo de produção/seleção, que cobre a atividade comumente denominada de coleta de dados; procedimento investigativo de registro, que é a disponibilização do material completo utilizado para a pesquisa; procedimento investigativo de interpretação do material, que em outras pesquisas é denominado resultado. Neste momento, utilizamo-nos da associação livre para criarmos/encontrarmos os campos de sentido afetivo-emocional das condutas. Por fim, o procedimento investigativo de interlocuções reflexivas, momento em que suspendemos o uso do método psicanalítico e revisitamos nossas interpretações para voltarmo-nos a um trabalho intelectual de caráter reflexivo (Ambrósio et al., 2013).

No primeiro passo, correspondente ao procedimento investigativo de produção/seleção do material, consideramos a possibilidade de utilização de blogs pessoais, material que pode ser comparado com as antigas narrativas de diários (Luccio \& Nicolacida-Costa, 2010), pois estes trazem como tema as vivências cotidianas de seus autores que, relatadas em primeira pessoa, promovem um tom intimista que favorece a troca emocional muito próxima do leitor (Petersen, 2015; Webb \& Lee, 2011). Aos leitores que se interessarem em conhecer mais sobre o uso de blogs em pesquisa qualitativa, recomendamos a leitura de Schulte et al. (2016b) e Visintin e Aiello-Vaisberg (2017).

Adotamos como critérios para a inclusão de postagens de blogs: a) relatar a experiência da maternidade, b) ter sido publicada durante um período de tempo pré-fixado, a saber de 01 a 30 de setembro de 2015 e c) estar disponível em blogs pessoais, nacionais e sem fim lucrativo. Partindo dos critérios acima, 0 resultado deste procedimento nos forneceu a soma de dez postagens.

Com o corpus em mãos, cuidamos de cumprir o procedimento investigativo de registro do material que se concretizou com o acesso às postagens para salvá-las em formato .doc. Em seguida, realizamos uma revisão em sua completude, a fim de excluirmos informações que possibilitassem a identificação de suas autoras.

O terceiro passo se deu por meio do método psicanalítico, utilizando-nos das premissas fundamentais da psicanálise: a associação livre e a atenção flutuante. Para tanto, consideramos como associação livre, nessa pesquisa, o material selecionado, ou seja, as postagens em blogs pessoais, que, por meio de sua leitura em estado de atenção flutuante, o psicanalista-pesquisador realizou a 
tarefa de interpretá-las psicanaliticamente. Assim, o conjunto do material foi lido sucessivas vezes cultivando a atenção flutuante. Tal processo foi repetido no contexto do grupo de pesquisa, não com o intuito de chegar a um tipo de consenso, mas visando enriquecer o processo interpretativo através de múltiplos olhares, possibilitando criar/encontrar os campos de sentido afetivo-emocional de tais condutas.

A quarta e última etapa é habitualmente intitulada, em pesquisas quantitativas ou qualitativas, que usam outros referenciais, como discussão de resultados. Como sabemos, a retomada das interpretações (ou resultados) é etapa essencial do processo investigativo. Neste momento, operamos uma suspensão do método psicanalítico para realizar um trabalho reflexivo sobre os campos criados/encontrados à luz de teorias e pensamentos de diferentes estudiosos, psicanalíticos ou não. Desta forma, procedemos a uma interlocução com autores que se voltaram a questões próximas ou idênticas àquelas apontadas pelos campos de sentido afetivo-emocional, tendo em vista ampliar nossa compreensão do fenômeno estudado que, no presente caso, é o da experiência de maternidade na contemporaneidade.

\section{RESULTADOS}

Apresentamos, nesta seção, os campos de sentido afetivo-emocional que produzimos interpretativamente a partir de impressões transferenciais geradas no encontro com as postagens selecionadas. Em outros termos, corresponde ao cumprimento do procedimento investigativo de interpretação do material. Um campo de sentido se define como espécie de região ou mundo emocional organizado ao redor de crenças, valores ou fantasias.

No âmbito desse estudo, a consideração psicanalítica das postagens permitiu a criação/encontro de dois campos de sentido afetivo-emocional que denominamos: "dedicando-se exclusivamente" e "conciliando atividades". Vale notar que tais campos não esgotam, de modo algum, a riqueza do material interpretado, já que todas as condutas humanas emergem provavelmente de múltiplos estratos ou camadas afetivo-emocionais. Entretanto, foram escolhidos por se terem evidenciado neste momento da trajetória do Grupo de Pesquisa como particularmente destacados e frutíferos no encaminhamento dos debates que têm a maternidade contemporânea e o sofrimento social como foco.

O primeiro campo de sentido afetivo-emocional criado/encontrado, que denominamos "dedicando-se exclusivamente", organiza-se a partir da crença de que a boa mãe é aquela que dedica todo o seu tempo ao seu filho e que faz dessa atividade sua única missão de vida. Evidências de condutas emergentes desse campo podem ser encontradas nos trechos a seguir:

Fatalmente deixamos de lado aquela mulher que fomos até então para nos transformarmos em um alguém que será o maior 
responsável por outro ser humano. Quer algo mais "metamorfoseador" que isso? (P3)

Tenho muito orgulho de cuidar sozinha do meu filho e não ser mãe de feriado, ou final de semana. No entanto, eu sei que nem toda mulher pode ficar exclusivamente cuidando de um filho. Existem mil empecilhos, principalmente a questão financeira. Milhares de mulheres precisam trabalhar para ajudar nas despesas domésticas. Eu nunca imaginei que seria mãe em tempo integral. Vivi até bem pouco tempo achando que eu tinha sido forjada para ocupar outro encargo. O destino me trouxe para experimentar o vortex [sic] da maternidade de maneira intensa, por pelo menos os primeiros 12 meses de vida do meu bebê. (P3)

Ter filhos é para educar, criar e cuidar. Não é para os avós, muito menos para as babás. Exige tempo, anulações, privações e exige muitaaa rotina. Sem falar nas noites mal ou bem mal dormidas. Nas comidas frias, choros e gritos constantes e certas vergonhas que aprendemos a conviver. [...]Filhos, filhos não são objetos e merecem serem tratados com muito respeito. Filhos foram feitos para serem criados pelos pais, com muito amor, educação e carinho. Lembre-se de que a responsabilidade é SUA e não da sua família, dindos, tias, primas, amigas, etc. (P4)

Éramos eu e meu filho. Meu filho e eu. Eu com minha nova vida, com minha nova pele, com meu novo corpo, meu novo compromisso, meus novos pensamentos, minhas novas sensações, meu novo eu. Com minha cria nos braços. [...] Eu e somente eu nutria meu bebê, que crescia com a ajuda do meu próprio leite. Aquilo para mim era algo quase surreal, algo incrível. (P10)

O segundo campo, "conciliando atividades", é um campo de sentido afetivo-emocional organizado ao redor da crença de que uma boa mãe pode cuidar de seu filho, aceitar ajuda para realizar tal cuidado e, ao mesmo tempo, manter outros interesses e atividades. Como podemos ver nos exemplos abaixo:

Eu consegui minha independência financeira cedo e não tinha, aliás, não tenho, equilíbrio emocional para lidar com a situação de ter que depender do meu marido para tudo que precisasse, no que diz respeito a dinheiro. Me restava então decidir como faria com a Nina quando retornasse da minha licença, que durou seis meses e mais um mês de férias, e aí acho que está o fator mais importante que fez a minha volta ao trabalho muito tranquila. Eu fiz uma escolha, não foi uma decisão sem alternativas, como acontece com muita gente. (P5)

O retorno ao trabalho após a maternidade gera muitas ansiedades e conflitos, na maioria das vezes isto significa em ficar longe do seu filho por um período fixo todos os dias. Este momento para muitas mães remete ao momento de repensar sua vida e sua carreira profissional, por isso vemos muitas mães que após a maternidade mudam completamente de profissão, modificam suas prioridades e necessidades, descobrem outros talentos e estratégias diferentes de trabalhar. (P7)

A mulher pode e deve manter sua vida profissional após a maternidade, mas, deve entender que as coisas jamais serão como antes. É necessário saber dividir, gerenciar o tempo, ou melhor, 
otimizar o tempo. É necessário gerenciar, confiar e saber delegar; sim é importante pedir ajuda e aceitar essa ajuda seja da babá, do berçário, da família ou do parceiro. (P9)

\section{DISCUSSÃO}

Os campos de sentido afetivo-emocional que produzimos interpretativamente a partir do estudo de postagens em blogs pessoais parecem confirmar nossa ideia da vigência da associação entre maternidade e sofrimento social. O primeiro campo, "dedicando-se exclusivamente", apresenta uma visão bastante conservadora acerca da maternidade, condizente com uma divisão de tarefas conjugais em termos das esferas pública e privada, dos domínios do patrimônio e do matrimônio, contra a qual as feministas vêm discutindo por não acreditarem que encerradas na vida doméstica realizam todo o seu potencial. Tal visão, como atestam as postagens estudadas, apesar de conservadora, segue se mantendo firme, num quadro bastante interessante, que combina o manejo de moderna tecnologia, a qual viabiliza a existência dos próprios blogs, com ideologias antigas, vale dizer, homem provedor, mulher cuidadora.

Por outro lado, um movimento interessante surge no horizonte quando nos deparamos com o segundo campo, "conciliando atividades". Este aponta para esforços de conciliação entre a vida profissional e a maternidade, algo que, como podemos bem imaginar, pode ser realizado de muitos modos, mas que sempre envolverá mudanças sociais. Esta última afirmação nos parece importante porque provavelmente apenas quando se puder reconhecer que os problemas de gênero afetam não apenas as mulheres, mas toda a sociedade, é que transformações significativas poderão ser alcançadas.

Muitas contribuições psicanalíticas, reconhecidamente importantes, como o pensamento winnicottiano, indiscutivelmente capaz de iluminar aspectos fundamentais da vida humana, principalmente no que diz respeito à constituição da subjetividade individual, parecem-nos comprometidas com o primeiro campo de sentido afetivo-emocional. Winnicott (1945/2000; 1956/2000; 1960/1998; $1963 / 1983 ; 1966 / 1999)$, cuja obra gira em torno do desenvolvimento emocional, aponta a mãe como a principal cuidadora de seus filhos e, sobretudo, indica sua característica insubstituível, salvo em condições extremas e/ou fatídicas. O autor traz a lume a tese de que a mãe, quando emocionalmente saudável, irá sofrer de "certa doença" para cuidar o máximo possível e da melhor maneira de seu bebê e, aos poucos, essa demanda diminui e ambos vão se separando, impulsionando o bebê para sua autonomia/independência. Winnicott (1956/2000) denomina este estado como "preocupação materna primária", defendendo-o como indispensável para que a mãe possa compreender as necessidades do filho e auxiliá-lo em sua integração, mas para isso é preciso estar totalmente dedicada a ele. Em suas palavras "é esta habilidade que faz com que a mãe saiba o que o bebê está sentindo. Nenhuma outra pessoa sabe" (Winnicott, 1960/1998, p.27). 
Não há dúvida de que é preciso situar tal contexto. Winnicott (1960/1998) trabalhava com mães e bebês ingleses no meio do século passado, quando a mãe era a principal cuidadora e o pai exercia outras atividades, principalmente prover o sustento da família e, quando em ambiente privado, sua função era a de apoiar a mulher-mãe a dedicar-se ao bebê, evitando interrupções neste relacionamento. Não surpreende, assim, que o autor exclua ou exima o pai das responsabilidades em relação ao bebê neste inicio da vida, em prol de um cuidado a ser exercido pela mãe, que deve ser bem assistida e não sofrer interferências em suas atividades. De acordo com sua teoria, os cuidados infantis devem ser cumpridos pela mãe, o que implica dizer que as mães devam se dedicar exclusivamente a atender as necessidades de seus filhos. Do nosso ponto de vista, o pensamento winnicottiano, tão inovador em vários aspectos, incorre num equívoco bastante sério ao atribuir a capacidade de cuidado a condições biológicas da progenitora, que facilitariam sua identificação com as necessidades do bebê, desconsiderando que a maternidade, como todo e qualquer fenômeno humano, seja socialmente produzida, haja vista os cuidados exercidos por avós, mães adotivas, mães sociais e, inclusive, pais cuidadosamente preocupados.

Outros autores, entre as quais lembramos Badinter (1985; 2010), Chodorow (1978) e Hollway (2006), também se debruçaram sobre o estudo da maternidade e, dentre a miríade de possibilidades que tal tema oferece, também abordam o que nosso primeiro campo de sentido afetivo-emocional, denominado "dedicando-se exclusivamente", expressa, vale dizer, a maternidade vivenciada enquanto um fazer exclusivo da mulher-mãe. Nesse campo, o que está sendo fortalecido é o modelo da família nuclear, que tanto se contrapõe às novas configurações familiares, que se vêm firmando desde o final do século $X X$, como às formas tradicionais de cuidado infantil, tais como aquelas estudadas por Gottlieb (2012) e Rogoff (2003/2005). Essas formas tradicionais se opõem à família nuclear na medida em que nelas encontramos que não apenas os pais se envolvem com o cuidado infantil, mas que esse pode ser compartilhado segundo diferentes arranjos, seguindo a ideia do provérbio africano de que para se criar uma criança é preciso uma vila.

Provavelmente, quando habitam o campo "dedicando-se exclusivamente", as mulheres são compelidas, hoje, em função do próprio movimento feminista, a proceder a uma atualização, pelo menos aparente, tendo em vista ao menos mascarar um posicionamento que poderia ser hoje considerado como francamente ultrapassado. É aqui que parece ganhar força o imaginário da boa mãe ecológica, adepta de práticas naturalistas supostamente mais saudáveis (Badinter, 2010). Não é difícil compreender este movimento, pois reivindicações ecológicas, de todo o tipo, surgem tanto em contextos progressistas como reacionários.

Assim, parece-nos que estamos lidando com os dois lados de uma mesma moeda, vale dizer, mundos vivenciais nos quais as mulheres-mães procuram ser 
boas mães mantendo a crença de que dedicar-se exclusivamente seria a melhor opção, mas que, por outro lado, sendo mulher, conciliar outras atividades, principalmente o trabalho, não a impediria de ser uma boa mãe. A diferença entre tais condutas aparenta ter como fundo não somente a intensidade da crença em relação ao cuidado materno, mas também o apoio que estas mulheres-mães encontram em seu contexto social.

\section{CONSIDERAÇÕES FINAIS}

Conforme nossa exposição inicial e nossa reflexão acerca dos campos afetivo-emocionais criados/encontrados, colocamos a questão do sofrimento social como intimamente ligado à contemporaneidade, pois exige a um só tempo que a mulher persista vivenciando a maternidade como se fosse sua única missão e destino, como se apresenta no campo "dedicando-se exclusivamente" mas, por outro lado, que também se engaje na vida laboral, encarregando-se de contribuir financeiramente para o sustento familiar e/ou desenvolvendo uma carreira profissionalmente significativa, como podemos ver no segundo campo "conciliando atividades". Trata-se, portanto, de uma situação que ocorre em diferentes classes sociais, em diferentes contextos culturais e em diferentes situações geopolíticas, apresentando-se, desse modo, como uma questão também de gênero.

Notamos, por conseguinte, algo absolutamente fundamental: a maternidade é contemporaneamente vivida como sofrimento social, pois acreditar na dedicação exclusiva à maternidade num mundo no qual as mulheres se preparam e buscam instrução para ocupar postos no mundo laboral e não mais "até o casamento" ou "para o caso de não conseguirem se casar", será causa de profundo mal-estar, pois desestabiliza o status quo de algumas situações configuradas socialmente e há muito tempo. Em contrapartida, se ganhar força a ideia de que é legítimo manter aspirações outras, para além da maternidade, como indica o segundo campo de sentido afetivo-emocional, estaremos nos encaminhando para uma transformação social importante acerca de como lidarmos com este evento.

A nosso ver, quanto mais forte for o primeiro campo de sentido afetivoemocional, "dedicando-se exclusivamente", levando a mulher a limitar sua existência ao exercício da maternidade, mais persistentemente se sustentará uma divisão social que conserva o pai na esfera pública e, consequentemente, impedido ou limitado de experienciar o contato cotidiano com os filhos e manterá a mulher-mãe confinada ao espaço privado, impedindo-a de vivenciar outras experiências. Não temos dúvidas de que nos encontramos diante de um arranjo que perpetua sofrimentos sociais que atingem a todos.

Vale aqui lembrar que a possibilidade de conciliar a maternidade se deve, também, a mudanças que ocorreram na esfera social, como a redução do 
número de filhos, uma das conquistas do movimento feminista a partir do surgimento dos anticoncepcionais. Por outro lado, os avanços científicos e tecnológicos passaram a exigir a contribuição financeira da mulher no sustento familiar. Consequentemente, a sociedade passou a valorizar a mulher que investe na carreira profissional, todavia, a contribuição para a conciliação da maternidade com outras atividades não foi acompanhada de mudanças nas atribuições de responsabilidade aos cuidados infantis, à medida em que esta ainda é tratada como uma atividade exclusivamente feminina.

Assim, é preciso salientar que a continuidade da espécie humana se dá com o evento da maternidade e com os cuidados dedicados às crianças, para que estas cresçam, preferencialmente, de modo saudável. Deste modo, ter filhos representa muito além da satisfação pessoal de casais, pois diz respeito à continuidade da presença humana na sociedade, da existência humana no planeta. Logo, os cuidados dispensados às crianças não devem ser tratados como um assunto privado, ao contrário, devem ser considerados uma questão social da mais alta relevância. Afinal, as mulheres, por se verem responsabilizadas constantemente pelo cuidado de crianças, podem encontrar dificuldades para a realização de suas potencialidades e, a longo prazo, desistirem massivamente da maternidade.

Também, no decorrer desse trabalho, concluímos que a maternidade é reinventada conforme cada época e em diferentes sociedades. Depreendemos ainda, que se tais mudanças são realizadas por seres humanos que compõem nosso contexto cultural, também são as mulheres que contribuem para este ou aquele modelo. Assim, faz parte de uma reinvenção da maternidade, a participação de mulheres-mães conscientes de suas posições tanto na sociedade quanto na família. Se estas não lutarem por mudança, não será a sociedade, ainda com resquícios de patriarcado e colonialismo, que proverá a transformação do status quo. Ou seja, se o modelo da maternidade como vemos na contemporaneidade é algo socialmente construído, é também passível de ser superado.

Apesar do presente estudo apresentar as limitações características das pesquisas qualitativas, é possível afirmar que o conhecimento que aqui produzimos, pode contribuir para a compreensão das demandas que aportam à clínica, mas também trazer subsídios para debates entre profissionais da saúde mental, cientistas sociais, ativistas de movimentos sociais, tais como o feminismo e, por fim, a sociedade civil como um todo. Lembramos, ainda, que este é um problema que afeta a todos, hoje e futuramente. 


\section{DECLARAÇÃO DE CONFLITOS DE INTERESSE}

Nós, Andréia de Almeida Schulte, Sueli Regina Gallo-Belluzzo e Tânia Maria José Aiello-Vaisberg, autoras do manuscrito intitulado "A experiência emocional de autoras de mommy blogs", declaramos que possuímos ( ) ou não possuímos $(X)$ conflito de interesse de ordem:

(X) financeiro,

(X) comercial,

(X) político,

(X) acadêmico e,

(X) pessoal,

Declaramos também que o material utilizado para o desenvolvimento deste trabalho está claramente informado no texto.

Campinas, 02 de maio de 2019

Autoras:

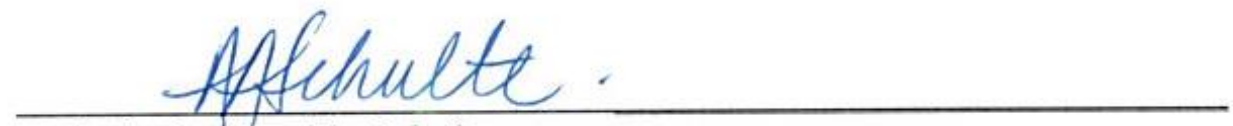

Andréia de Almeida Schulte
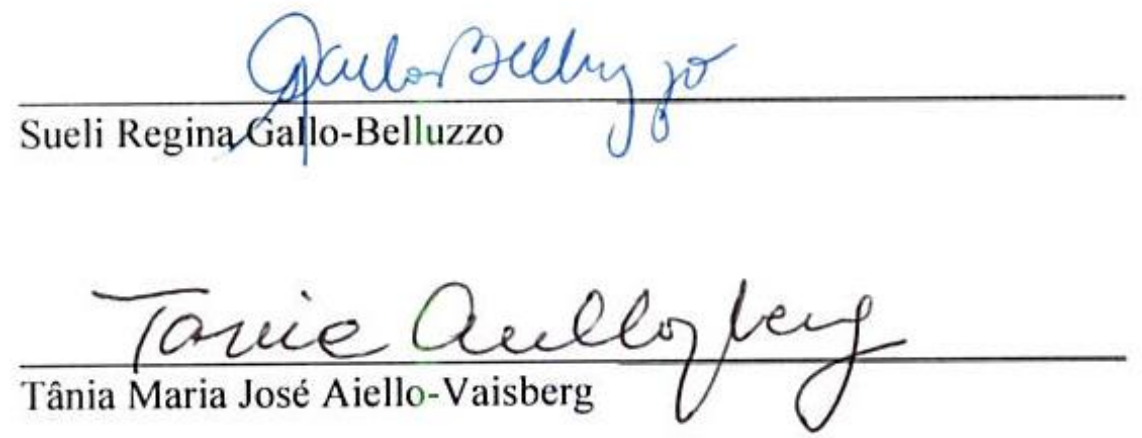


\section{REFERÊNCIAS}

Affonso, R. M. L., \& Mota, E. G. (2002). A relação pais-filhos: Um estudo da dinâmica familiar. Psikhe, 7(1), 48-56.

Aiello-Vaisberg, T. M. J. (2001). A função social da psicologia clínica da contemporaneidade. Revista Psicologia: Teoria e Prática, 3(1), 93-99. Recuperado em 29 de abril de 2019, de http://editorarevistas.mackenzie.br/index.php/ptp/article/view/1103/814.

Aiello-Vaisberg, T. M. J. (2017). Estilo Clínico ser e fazer: Resposta críticopropositiva a despersonalização e sofrimento social. Boletim: Academia Paulista de Psicologia, 37(92), 41-62. Recuperado em 29 de abril de 2019, de $\quad$ http://pepsic.bvsalud.org/scielo.php?script=sci arttext\&pid=S1415711X2017000100005\&lng=pt\&tlng=pt.

Amaral, M. F., \& Bispo, T. C. F. (2016). Mães e filhos atrás das grades: Um olhar sobre o drama do cuidar de filhos na prisão. Revista de Enfermagem Contemporânea, 5(1), 51-58. http://dx.doi.org/10.17267/23173378rec.v5i1.836.

Ambrósio, F. F., Aiello-Fernandes, R., \& Aiello-Vaisberg, T. M. J. (2013, Dezembro). Pesquisando sofrimentos sociais com o método psicanalítico: Considerações conceituais. In L. S. L. P. C. Tardivo, \& T. M. Aiello-Vaisberg, J. (Eds.), Anais da XI Jornada Apoiar Adolescência: Identidade e sofrimento na clínica social. Instituto de Psicologia/USP. São Paulo, SP.

Ancona-Lopez, M. (1983). Considerações sobre o atendimento fornecido por clínicas-escola de psicologia. Arquivos Brasileiros de Psicologia, 35(2), 123135. Recuperado em 29 de abril de 2019, de http://bibliotecadigital.fgv.br/ojs/index.php/abp/article/view/18922/17664.

Badinter, E. (1985). Um amor conquistado: O mito do amor materno. Rio de Janeiro, RJ: Nova Fronteira.

Badinter, E. (2010). Le conflit: La femme et la mère. Paris, França: Flammarion.

Beauvoir, S. (1980). O Segundo Sexo (Vols. 1-2). (S. Milliet, Trad.). Rio de Janeiro, RJ: Nova Fronteira. (Original publicado em 1949).

Bleger, J. (1984). Psicologia da conduta. (E. O. Diehl, Trad.). Porto Alegre, RS: Artes Médicas. (Original publicado em 1963).

Chodorow, N. (1978). The reproduction of mothering. Berkley, CA: University of California Press.

Collin, F., \& Laborie, F. (2009). Maternidade. In H. Hirata, F. Laborie, H. Doaré, \& D. Senotier (Eds.), Dicionário critico do feminismo. (pp. 133-138). São Paulo, SP: Editora UNESP.

Corbett, E. (2014) Contos sem fadas: mães e filhos em situação de violência doméstica (Tese de doutorado, PUC-Campinas). Recuperado em 29 de abril de 2019, de http://tede.bibliotecadigital.puccampinas.edu.br:8080/jspui/bitstream/tede/462/1/Elisa\%20Corbett.pdf. 
Couto, T. H. A. M., Tachibana, M., \& Aiello-Vaisberg, T. M. J. (2007) A mãe, o filho e a síndrome de Down. Paidéia (Ribeirão Preto), 17(37), 265-272. http://dx.doi.org/10.1590/S0103-863X2007000200010.

Dejours, C. (1993) Travail, usure mentale. De la psychopathologie à la psychodynamique du travail. Paris, França: Bayard. (Original publicado em 1980).

Dejours, C. (1998). Souffrance en France: La banalisation de l'injustice sociale. Paris, França: Editions du Seuil.

Fougeyrollas-Schwebel (2009). Movimentos feministas. In H. Hirata, F. Laborie, H. Doaré, \& D. Senotier (Eds.), Dicionário critico do feminismo. (pp. 144149). São Paulo, SP: Editora UNESP.

Freud, S. (1996). Estudos sobre histeria: Emmy von N. In S. Freud, Edição standard brasileira das obras psicológicas completas de Sigmund Freud (vol. II). Rio de Janeiro, RJ: Imago. (Original publicado em 1895).

Freud, S. (1996). A história do movimento psicanalítico. In S. Freud, Edição standard brasileira das obras psicológicas completas de Sigmund Freud (vol. XIV). Rio de Janeiro, RJ: Imago. (Original publicado em 1914).

Freud, S. (1996). Conferência XXII: Algumas ideias sobre desenvolvimento e regressão: Etiologia. In S. Freud, Edição Standard Brasileira das Obras Psicológicas Completas de Sigmund Freud (vol. XVI). Rio de Janeiro, RJ: Imago. (Original publicado em 1917).

Freud, S. (1996). Dois verbetes de enciclopédia. In S. Freud, Edição standard brasileira das obras psicológicas completas de Sigmund Freud (vol. XVIII). Rio de Janeiro, RJ: Imago. (Original publicado em 1922).

Freud, S. (1996). Algumas consequências psíquicas da distinção anatômica entre os sexos. In S. Freud, Edição standard brasileira das obras psicológicas completas de Sigmund Freud (vol. XIX). Rio de Janeiro, RJ: Imago. (Original publicado em 1925).

Gallo-Belluzzo, S. R., Corbett, E., \& Aiello-Vaisberg, T. M. J. (2013). The first experience of clinical practice on psychology students' imaginary. Paidéia (Ribeirão Preto), 23(56), 389-396. doi:10.1590/1982-43272356201313

Garcia, C. C. (2011). Breve história do feminismo. São Paulo, SP: Claridade.

Gottlieb, A. (2012). Tudo começa na outra vida. A cultura dos recém-nascidos no oeste da África. São Paulo, SP: Editora Fap-Unifesp.

Granato, T. M. M., \& Aiello-Vaisberg, T. M. J. (2009). Maternidade e colapso: Consultas terapêuticas na gestação e pós-parto. Paideia, 19(44), 395-401. http://dx.doi.org/10.1590/S0103-863X2009000300014.

Granato, T. M. M., \& Aiello-Vaisberg, T. M. J. (2011). Uso terapêutico de narrativas interativas com mães em situação de precariedade social. Psico, 42(4), 494-502. Recuperado em 29 de abril de 2019, de http://revistaseletronicas.pucrs.br/ojs/index.php/revistapsico/article/view/7 $122 / 7456$. 
Herrmann, F. (2004). Pesquisando com o método psicanalítico. In F. Herrmann, \& T. Lowenkron (Eds.), Pesquisando com o método psicanalítico. (pp. 4383). São Paulo, SP: Casa do Psicólogo. (Original publicado em 1979).

Hollway, W. (2006). The capacity to care: Gender and ethical subjectivity. London, England: Routledge.

Kleinman, A., Das, V., \& Lock, M. (Eds.). (1997). Social Suffering, Berkeley, CA: University of California Press.

Luccio, F., \& Nicolacida-Costa, A. (2010). Blogs: de diários pessoais a comunidades virtuais de escritores/leitores. Psicologia: Ciência e Profissão, 30(1), 132-145. http://dx.doi.org/10.1590/s1414-98932010000100010.

Melo, S. A., \& Perfeito, H. (2006). Características da população infantil atendida em triagem no período de 2000 a 2002 numa clínica-escola. Estudos de Psicologia (Campinas), 23(3), 239-249. http://dx.doi.org/10.1590/S0103166X2006000300003.

Merg, M. M. G. (2008). Características da clientela infantil em clínica-escola. (Dissertação de Mestrado), PUC do Rio Grande do Sul, RS. Recuperado em 29 de abril de 2019, de http://repositorio.pucrs.br/dspace/bitstream/10923/4972/1/000411813Texto\%2bCompleto-0.pdf.

Miguel, L. F., \& Biroli, F. (2014) Feminismo e política: Uma introdução. São Paulo, SP: Boitempo.

Nascimento, A. O., \& Faro, A. (2015). Estratégias de enfrentamento e o sofrimento de mães de filhos com paralisia cerebral. Revista Latinoamericana de Psicologia de la Salud y Social, 6 (3), 195-210. http://dx.doi.org/10.22199/S07187475.2015.0003.00001.

Petersen, E. J. (2015). Mommy bloggers as rebels and community builders: A generic description. Journal of the Motherhood Initiative for Research and Community Involvement, 6(1), 9-30. Recuperado em 29 de abril de 2019, de

https://jarm.journals.yorku.ca/index.php/jarm/article/view/40238/36420.

Pinsky, C. B., \& Pedro, J. M. (ed.) (2012). Nova história das mulheres no Brasil. São Paulo, SP: Contexto.

Politzer, G. (1998). Crítica dos fundamentos da psicologia: A psicologia e a psicanálise. (M. Marcionilo, \& Y. M. C. T. da Silva, Trads.). Piracicaba, SP: Editora Unimep. (Original publicado em 1928).

Renault, E. (2004). L'expérience de l'injustice. Reconaissance et clinique de I'injustice. Paris, França: La Découverte.

Renault, E. (2008). Souffrances sociales. Sociologie, psychologie et politique. Paris, França: La Découverte.

Rogoff, B. (2005). A natureza cultural do desenvolvimento humano. (R. C. Costa, Trad.). Porto Alegre, RS: Artmed. (Original publicado em 2003). 
Scabio, J. (2016). Sofrimento, fé e justiça: Um estudo sobre um grupo de mães de vítimas de acidentes de trânsito e de violência policial. Dilemas: Revista de Estudos de Conflito e Controle Social, 9(1), 111-140. Recuperado em 29 de abril de 2019, de https://revistas.ufrj.br/index.php/dilemas/article/view/7675/6187.

Scavone, L. (2001) Maternidade: Transformações na família e nas relações de gênero. Interface - Comunicação, Saúde, Educação, 5(8), 47-60. http://dx.doi.org/10.1590/S1414-32832001000100004.

Scavone, L. (2004). Dar a vida e cuidar da vida: Feminismo e ciências sociais. São Paulo, SP: Editora Unesp.

Schulte, A. A. (2016). Maternidade contemporânea como sofrimento social em blogs brasileiros. (Dissertação de Mestrado, PUCCampinas). Recuperado em 29 de abril de 2019, de: http://tede.bibliotecadigital.puccampinas.edu.br:8080/jspui/bitstream/tede/892/2/Andreia\%20de\%20Almei da\%20Schulte.pdf

Schulte, A. A., Gallo-Belluzzo, S.R., \& Aiello-Vaisberg, T. M. J. (2016a, Dezembro). Experiência emocional sobre a maternidade veiculada em blogs brasileiros: Considerações iniciais. In L. S. L. P. C. Tardivo, \& T. M. J. AielloVaisberg (Eds.), Anais da XIV Jornada Apoiar "Saúde mental e interdisciplinaridade: Propostas e pesquisas, IP/USP. São Paulo, SP.

Schulte, A. A., Gallo-Belluzzo, S. R., \& Aiello-Vaisberg, T. M. J. (2016b). Postagens em blogs pessoais: Aproximação do acontecer humano em pesquisas psicanalíticas. Psicologia Revista, 25(2), 227-241. Recuperado em 29 de abril de 2019, de https://revistas.pucsp.br/psicorevista/article/view/30138/21350.

Segeren, L., \& Françozo, M. F. C. (2014). As vivências de mães de jovens autistas. Psicologia em Estudo, 19(1), 39-46. http://dx.doi.org/10.1590/1413-7372207840004.

Tain, L. (2005). Um filho quando eu quiser? O caso da França contemporânea. Estudos Feministas, 13(1), 53-67. Recuperado em 29 de abril de 2019, de http://www.scielo.br/pdf/ref/v13n1/a04v13n1.pdf.

Vázquez, G. (2014). Maternidade e feminismo: Notas sobre uma relação plural. Revista Trilhas da História, 3(6), 167-181. Recuperado em 29 de abril de 2019, de http://seer.ufms.br/index.php/RevTH/article/view/472/273.

Visintin, C. D. N., \& Aiello-Vaisberg, T. M. J. (2017). Motherhood and social suffering in Brazilian mommy blogs. Revista Psicologia: Teoria e Prática, 19(2), 108-116. $\quad$ http://dx.doi.org/10.5935/19806906/psicologia.v19n2p108-116.

Webb, L. M., \& Lee, B. S. (2011). Mommy blogs: The centrality of community in the performance of online maternity. In M. Moravec (Ed.), Motherhood online (pp. 244-257). Newcastle upon Tyne, UK: Cambridge Scholars Publishing. 
Winnicott, D. W. (2000). Desenvolvimento emocional primitivo. In D. W. Winnicott. Da pediatria à psicanálise: Obras escolhidas. (D. Bogomeletz, Trad.). (pp. 218-232). Rio de Janeiro, RJ: Imago. (Original publicado em 1945).

Winnicott, D. W. (2000). Preocupação materna primária. In D. W. Winnicott. Da pediatria à psicanálise: obras escolhidas. (D. Bogomeletz, Trad.). (pp. 340405). Rio de Janeiro, RJ: Imago. (Original publicado em 1956).

Winnicott, D. W. (1998). O relacionamento inicial da mãe com o filho. In D. W. Winnicott. A família e o desenvolvimento do indivíduo, Belo Horizonte, MG: Interlivros. (Original publicado em 1960).

Winnicott, D. W. (1983). Comunicação e falta de comunicação levando ao estudo de certos opostos. In $\mathrm{D}$. W. Winiccott. $O$ ambiente e os processos de maturação: Estudos sobre a teoria do desenvolvimento emocional. (I.C.S. Ortiz, Trad.). (pp. 163-174). Porto Alegre, RS: Ed. Artmed. (Original publicado em 1963).

Winnicott, D. W. (1999). A mãe dedicada comum. In D. W. Winnicott. Os bebês e suas mães. (J. L. Camargo, Trad.). (pp. 1-11). São Paulo, SP: Martins Fontes. (Original publicado em 1966).

Yoshida, E. M. P., Gatti, A. L., \& Xavier, I. A. (1994). Avaliação do perfil e das queixas de crianças encaminhadas para psicoterapia dinâmica breve. Estudos de Psicologia, 11(3), 27-33.

Sobre as autoras

Andréia de Almeida Schulte é Mestre em Psicologia pela Pontifícia Universidade Católica de Campinas e Doutoranda pela Michigan School of Psychology.

quantaandreia@hotmail.com

Sueli Regina Gallo-Belluzzo é Doutora em Psicologia pela Pontifícia Universidade Católica de Campinas. suelibelluzzo@gmail.com

Tânia Maria José Aiello-Vaisberg é Professora Livre Docente pelo Instituto de Psicologia pela Universidade de São Paulo. Orientadora dos Programas de PósGraduação em Psicologia da Pontifícia Universidade Católica de Campinas e do Instituto de Psicologia da Universidade de São Paulo e recebe financiamento de pesquisa pelo CNPq. Coordenadora da "Ser E Fazer": Oficinas Psicoterapêuticas de Criação do IPUSP. aiello.vaisberg@gmail.com

Certificamos que todos os autores participaram suficientemente do trabalho, para tornar pública sua responsabilidade pelo conteúdo, uma vez que o artigo deriva de dissertação de mestrado defendida por A.A.S., orientada por T.M.J.A.V., e acompanhada em todas as etapas de sua realização por S.R.G.B., que também supervisionou o material. A contribuição de cada autor pode ser atribuída como se segue: A.A.S, S.R.G.B. e T.M.J.A.V. contribuíram para a conceitualização, investigação e visualização do artigo; A.A.S foi a responsável 
pela obtenção de financiamento; A.A.S e S.R.G.B fizeram a redação inicial do artigo (rascunho) e A.A.S, S.R.G.B. e T.M.J.A.V. são os responsáveis pela redação final (revisão e edição).

Ademais, os autores agradecem à Coordenação de Aperfeiçoamento de Pessoal de Nível Superior (CAPES) pelo financiamento da pesquisa.

Recebido em: 10/04/2017

$1^{\text {a }}$ revisao em: $17 / 10 / 2017$

Aceito em: 12/01/2018 